\title{
PARA UNA TEORÍA DE LOS GÉNEROS EN VENEZUELA: EL CASO DE LA NOVELA Y EL ENSAYO
}

\author{
POR \\ Miguel Gomes \\ The University of Connecticut-Storrs
}

No es un esfuerzo inútil intentar discernir la existencia de una tradición hispanoamericana de crítica de los géneros. Y cuando empleo el término "crítica", no me refiero únicamente a discursos paraliterarios que reflexionan acerca de la obra literaria, sino también a los discursos leídos como literatura que, de una manera u otra, meditan sobre los límites y alcances del arte de la palabra o contribuyen decisivamente a moldear puntos de vista 0 preferencias de una época en torno a semejantes problemas. Toda genología ${ }^{1}$ constituye, hasta cierto punto, una labor lingüística, si se percibe que la elección de una variedad de escritura equivale a la opción por un lenguaje entre muchos posibles para establecer entre autor y lectores una "comunicación" o "pseudocomunicación" literaria. ${ }^{2}$ De hecho, tanto emplear una modalidad expresiva tradicional como tratar de inventar una nueva fundan en gran medida el acto de creación y la lectura, pues determinan a través de un tejido de convenciones qué se ha de perseguir al escribir o qué se ha de esperar al leer. Los vínculos entre un texto específico y "su" género - 0 , por contraste, los géneros a los que no "pertenece"- se convierten entonces en una fuente inagotable de sentido que no podemos eludir.

\footnotetext{
${ }^{1}$ Sobre la "genología" o estudio de los géneros véase Claudio Guillén (1985): 141-81. La noción de género que manejo en estos apuntes, aunque casi siempre coincide con la de Guillén, participa a veces de lo que éste denomina "forma" (184-247): en determinados momentos de la historia ciertos géneros han sido identificados con formas concretas -el drama con el diálogo, para no ir muy lejos, pese a que otras épocas reconozcan que la pantomima es tan "dramática" como el intercambio verbal. En todo caso, una distinción no muy precisa de ambos conceptos, paradójicamente, nos podrá ser útil para entrever cómo se producen traspasos de material expresivo entre novela y ensayo en los textos que comentaremos. El efecto de lectura "mixta" que ha experimentado el público ante ciertas obras, frecuentemente calculado por el escritor, depende la mayoría de las veces de atribuciones formales fijas a los géneros - por ejemplo: novela=narración, ensayo=exposición.

${ }^{2}$ Remito al lector interesado en una fenomenología del texto literario al libro de Félix MartínezBonati Fictive Discourse and the Structures of Literature (1981). De Martínez-Bonati tomo la distinción entre la comunicación lingüística real y la comunicación ficticia o hipotética que se produce en el lenguaje "potencial" de la literatura.
} 
Lejos estoy de proponer una revisión estructuralista del pensamiento genológico hispanoamericano. La noción de estructura, con la percepción consecuente de sistemas estáticos de afinidad y oposición, si bien ha sido valiosa durante varios decenios, resulta a estas alturas cada vez más estéril al estrechar innecesariamente la riqueza del análisis histórico del texto. La presencia de una idea del género tanto en la producción como en la recepción de la obra es una forma de historia, puesto que la vinculación de la escritura con las abstracciones caracterológicas prevalecientes en su época de nacimiento y en la posteridad configura distintas modernidades: la historicidad del Quijote, por ejemplo, es una causa y una consecuencia de las interpretaciones barrocas, neoclásicas, románticas, noventayochistas y contemporáneas que se han hecho de él y que él ha hecho factibles, sin obviar el papel que ha desempeñado al suscitar distintas concepciones de la novela o de la "ficción" a través del tiempo. Creo que una manera más discreta de meditar acerca de los géneros no es contrastarlos o distinguirlos unos de otros, sino más bien intentar ponerlos a dialogar para comparar así, en medio de un espacio intertextual, las divergencias que sólo las coincidencias pueden hacer notar. El pasado y el presente de una variedad literaria se aclaran cuando descubrimos las distintas alternativas de escritura entre las que se ha debatido un texto: el "otro" género fue, de cierto modo, una posibilidad pretérita que la forma adoptada, en su aquí y ahora, define silenciosamente.

Se me ocurre que la teoría de los géneros en Hispanoamérica ha tenido a su disposición y ha contribuido a elaborar una serie de modelos crítico-creadores entre los que se destacan cuatro principales que denominaré, por lo pronto, "mimético", "transitivo", "pantextual" y "nihilista". Estos modelos no son propios de un período particular: aparecen y reaparecen aquí y allá nunca exactamente iguales, ajustándose a distintas circunstancias o necesidades inmediatas de escritores y lectores. Reutilizables según el medio, el momento y el usuario, son "métodos" tanto o más que "ideologías".

Una teoría mimética de los géneros es aquélla en la que las diversas formas están enlazadas a las claras o subrepticiamente con visiones trascendentes de lo literario. Para ella, en el fondo, existen esencias inmutables que explican la persistencia de ciertos fenómenos de escritura a través de los siglos. Por supuesto, es el modelo que predomina en las letras occidentales desde la Grecia antigua hasta el siglo XVIII, y en las hispanoamericanas poscoloniales durante el neoclasicismo, prolongado por la tradición académica posterior a la que se opusieron, con grandes polémicas sucesivas, románticos, modernistas y vanguardistas: una y otra vez, la razón de ciertas tipologías (lírica-épicadrama, tragedia-comedia, prosa-poesía, entre otras) tácitamente parece encontrarse, cuando no en el "mundo de las ideas", en la naturaleza humana, más o menos "constante". No es necesario remitirnos a Aristóteles, a Diomedes o a Goethe para encontrar casos memorables de esta creencia en el reflejo fiel de lo humano en la superficie especular de la literatura. En plena segunda mitad del siglo XX y en los Estados Unidos, un crítico de las literaturas hispánicas aún puede afirmar:

It is all but impossible to invent a new form of writing. Authors such as Borges and Cortázar may change the ancient classic design of short story [sic] to produce unusual approaches to brief fiction, but even so, a short story remains a short story, no matter how it may be manipulated or distorted for effect (J. E. Keller apud Lévy-Loveluck 94). 
Otra variante reciente de la postura mimética es la de los formalistas y estructuralistas, que pretendieron ver en las diferencias entre géneros literarios una reproducción de tensiones dicotómicas presentes en la lengua. La naturaleza o el universo copiados, de esta manera, se convierten en el lenguaje, categoría ontológica absoluta de la que dependen todas las otras que el hombre maneja, incluso los géneros. Pero ya antes, cuando André Jolles definía "formas simples" de la literatura, por ejemplo, cimentaba su tipología en nociones lingüísticas como "interrogación", "afirmación", "silencio", "imperativo" u "optativo". No es de extrañar, entonces, que la discusión genológica haya sido confundida no sólo por él sino por muchos otros investigadores del siglo XIX y el XX con una rama de la morfología gramatical.

El segundo gran modelo que se divisa en nuestra historia, el "transitivo", es también de abolengo clásico y medieval. El aprendizaje a través del deleite predicado por Horacio y practicado en El conde Lucanor, para mencionar sólo un caso temprano en la tradición de lengua española, interviene en la teoría de los géneros cuando se intenta aprovechar al máximo la utilidad en potencia de cada tipo literario. Puesto que la misión del texto es transformar el mundo, los géneros resultan ser distintos medios o estrategias para llevar a cabo ese propósito. El afán neoclásico e ilustrado de instruir al lector podía dar pie, para no ir muy lejos, a poemas o dramas sobre la vacuna y la medicina (piénsese en Quintana o Bello) que otras épocas difícilmente considerarían siquiera pertenecientes al orbe de lo "poético" o lo "dramático", situándolos más bien entre las formas tratadísticas o ensayísticas. Una crónica rimada de la Colonia, como las Elegías de los varones ilustres de Juan de Castellanos, puede ser recibida en el siglo XX - me refiero al Picón-Salas de Formación y proceso de la literatura venezolana - como una compilación de "novelas y cuentos en estado larvario" sencillamente porque el tipo que la originó ha desaparecido y porque la función informativa y formativa inicial del texto ha sido retomada en nuestros días, con mucha más eficacia, por los estudios históricos. Un modelo de percepción y producción genérica, para poder asimilarlas y adaptarlas a sus intereses, recategoriza obras del pasado que no se ajustan a él.

El siglo XIX en Hispanoamérica es especialmente fértil en ejemplos de la metamorfosis de los patrones transitivos, que participan como protagonistas de las estéticas neoclásica, romántica y realista-naturalista. Si la transformación del mundo en la primera adoptaba la postura de iluminar intelectualmente al lector, la de la segunda solía conminar a la acción inmediata o a la revisión pasional de los valores tradicionales; la de la tercera, por su parte, se empeñaba en diagnosticar los males americanos con el fin de conmover al público y disponerlo a procurar el cambio. En cuanto a la producción de obras literarias, tanto el neoclasicismo como el realismo-naturalismo intentaban con frecuencia confiar en formas "transparentes", identificables con algunas previas por parte del lector, que no impidieran por consiguiente la comprensión rápida de trasfondos ideológicos "comunicados" mediante la escritura: los experimentalismos en piezas de este corte escasean, pues la confusión que lo novedoso podía ocasionar desviaba la atención hacia una referencialidad de importancia primordial. Sin duda, es por eso por lo que el realista Alberto Blest Gana hacia 1861, en su célebre discurso Literatura chilena, señala la imposibilidad del triunfo de novelas o cuentos "fantásticos" en Chile, pues no había un público preparado para ellos; Blest Gana, como novelista, en cambio, prefiere el cultivo de obras de "costumbres político-sociales", con 
las que sus lectores de un modo $\mathrm{u}$ otro estaban familiarizados y que podían aprovechar fácilmente. Esta preferencia no es identificable tan abiertamente entre los románticos, que fusionaron o forzaron formas tradicionales para subrayar la índole renovadora de los tiempos: por algo, muchos atribuyen a ellos el nacimiento de la modernidad filosófica y artística. Cuando Simón Rodríguez tendía puentes entre la pintura —orbe extraliterario incluso- y el ensayo en sus Sociedades americanas, estaba refundiendo su formación iluminista en una empresa de corte romántico. Cuando Sarmiento escribía autobiografías y ensayos "novelescos", hacía otro tanto, pues ponía en el foco de atención de todo un continente formas novedosas o marginales en las literaturas hispánicas. Cuando José Hernández hacía "héroe" de su poema narrativo a un gaucho miserable, subvertía asimismo lo que los neoclásicos como Olmedo entendían por "épica", y creaba algo que, a falta de otro nombre, es inteligible como una epopeya picaresca o costumbrista - como en la tragicomedia, el estilo elevado y el bajo se encontraban sorprendentemente en una sola entidad verbal ... El pathos romántico es capaz de deformar y sacudir el orden genérico establecido; la actitud ante las convenciones preexistentes es individualista, y parte del universo por renovar desde esa perspectiva es el esquema de los tipos literarios. Lo que está en primer plano es el deseo de intervenir en la realidad; las tradiciones de escritura, por tanto, pasan a un segundo plano de interés o son reformadas para que abarquen un entorno moderno, distinto, y penetren en él.

Los modelos genéricos transitivos siguen presentes en el siglo XX: el mundonovismo a lo Gallegos o Picón-Salas, al adoptar puntos de vista magisteriales, sigue la estrategia neoclásica o realista-naturalista. Las formas, poco experimentales, no estorban con textualismos asombrosos la intelección del mundo representado. Basta pensar en la visión más corriente que se tiene en Venezuela de Gallegos, confirmada mil veces por múltiples críticos y comentaristas: el epíteto de "maestro" lo acompaña no menos que la definición antonomástica de "novelista" nacional. El neorrealismo que supone la reciente literatura testimonial en todo el continente, por otra parte, llega al extremo de desdeñar inclusive la reflexión sobre el probable ser novelesco de la obra, como puede apreciarse en las palabras introductorias del editor de Biografia de un cimarrón: el carácter artístico o no de la escritura es secundario y cuentan más sus objetivos, su función —el pensamiento genérico se manifiesta a la inversa, por omisión de la noción de género: el tipo que tenemos entre manos, entonces, puede entenderse como literatura instrumental, distinguible del relato, el reportaje, el tratado, etc. La funcionalidad llevada a sus extremos produce una "aliteratura".

Contra mimesis y transitividad reacciona el tercer modelo, que he denominado pantextual. Si el mimético adoptaba las formas del mundo, éste hará que el mundo adopte las formas de la literatura. Si el transitivo hacía de la escritura una herramienta de intervención en el exterior del texto, éste hará del universo una operación literaria más, un elemento más del cuerpo textual. En su Celebración del modernismo, Saúl Yurkievich ha dicho que el imperativo de ese movimiento era literaturizar cuanto pasaba por las manos del escritor. De la consustanciación de mundo y escritura, entonces, dependerá también la teoría de los géneros de los modernistas, en la que los traspasos, las combinaciones y las mezclas fueron incontables. La figura de Proteo, tal como la definió Rodó, emblematiza esa práctica. Con Darío, además, tendríamos ya pruebas de sobra de que los tipos literarios eran objetos por mestizar más que objetos por discriminar: están allí sus cuentos poéticos, 
desnarrativizados al máximo, así como sus poemas en prosa o sus poemas dialogados que, aunque existían como tradiciones, indican una intencionalidad clara si pensamos que fueron escogidos entre múltiples opciones que ofrecía la historia literaria. El evanescente caos universal de fines del siglo XIX y principios del XX, producido por la filosófica "muerte de los dioses" tiene su correlato en esta desaparición de las certidumbres genéricas conocidas hasta la fecha.

El último modelo que hemos distinguido, el nihilista, es una consecuencia inmediata del anterior. La deidad modernista, el arte, centro del mundo, perece también en cuestión de varios decenios, y toca a las vanguardias dar cuenta de esa agonía. La idea de la nada, de la negación total de los valores, está presente en escritores y críticos que hablan de la "antinovela" o la "antipoesía". La reflexión sobre los géneros se plantea, por consiguiente, como aniquilamiento de los géneros existentes más que como su combinación fértil con miras a adentrarse en el futuro. Un fenómeno con que no contaron los primeros vanguardistas tuvo lugar, no obstante, con el paso de los años: la institucionalización de sus asesinatos rituales, es decir, su conversión en literatura corriente y moliente. Asistimos a ese momento, ni más ni menos, en las postrimerías del siglo XX y los inicios del XXI: semejante descubrimiento de que el cultivo de la negación implica una nueva afirmación ha provocado, como último recurso para olvidar la empresa vanguardista, una convergencia reaccionaria y enmarañada de creencias y gustos ya descartados anteriormente. No es de extrañar, así, que se descubran manierismos y reiteraciones en varias novelas del postboom o en las tendencias testimoniales a las que he aludido, que recuperan furibundis modis la transitividad decimonónica, para no mencionar el mimetismo, puesto que el tipo "testimonio" parece fundarse sobre una copia - retórica al fin y al cabo, como no será difícil adivinar- del universo exterior: la oralidad "convertida", utópica y engañosamente, en literatura.

\section{II}

El propósito de las páginas precedentes no es formular de manera definitiva una genología hispanoamericana: una labor de esa envergadura requeriría mucho más que unos pocos párrafos. Lo que se propone la distinción de cuatro modelos básicos de apreciación de los géneros es sustentar el breve estudio que haremos a continuación de los encuentros y desencuentros en la tradición venezolana contemporánea de dos de sus tipos literarios centrales: la novela y el ensayo. ¿Qué criterios han seguido escritores que cultivan ambos a la hora de elegir una alternativa de expresión u otra? ¿Qué sentido estético e ideológico tiene la elección? ¿En qué comulgan los textos así disgregados? ¿Cómo han actuado los cuatro modelos genológicos en la configuración de esta intertextualidad?

Creo que el primer autor relevante tanto de novelas como de ensayos que aporta Venezuela a Hispanomérica es Manuel Díaz Rodríguez. Sus lectores estuvieron en muchos países del continente e, incluso, la presencia de sus libros en España ha dejado rastros críticos nada desdeñables. Una de las muestras más notables de su reflexión en torno a la naturaleza de las formas literarias se la debemos a una polémica que sostuvo hacia 1906, con motivo de su novela Ídolos rotos (1901). Ésta, según Gonzalo Picón-Febres en La 
literatura venezolana del siglo $X I X$, olía " a odio en todos sus capítulos ... Para el protagonista Alberto Soria, tanto como para Díaz Rodríguez, cuyos temperamentos puede decirse que son coesenciales, todo en Caracas es atroz": a semejantes aseveraciones, el novelista respondió esbozando una serie de razonamientos que han sido hechos moneda corriente sólo por críticos literarios posteriores:

Hame asaltado una duda sobre el derecho que pueda tener el crítico de atribuir al autor los sentimientos e ideas de sus personajes ... Quién sabe si presentándonos ingenuamente desnudos, como los niños, haríamos obra más original ... Sólo que en ese caso abandonaríamos el teatro, el cuento y la novela, en los que forzosamente se agitan sentimientos, ideas y personajes contradictorios, para acudir a otras formas de arte. Pero mientras cultivemos tales géneros literarios como los entendemos hoy, creo que el crítico no tiene derecho a ver al autor en ninguno de sus personajes, comparsa o protagonista ... (Sermones 167-8).

Notemos que la narrativa y el drama comparten dos elementos: presencia de personajes y distinción enunciativa entre tales seres de ficción y el ser de carne y hueso que los crea. El hecho de que Díaz Rodríguez suprima de su lista la poesía y el ensayo puede dar a entender que estas "otras formas de arte" - poco soslayables en el período modernistano coinciden en dichos puntos con las mencionadas; esto implicaría la supervivencia en su sistema genérico personal de una idea romántica de la lírica (identificación "sincera", "pasional" entre hablante y autor) y una concepción del género ensayo como variedad de la prosa opuesta a la narrativa y el teatro, ya que en ella hay ausencia de personajes y distancia fenomenológica entre voz ficticia y escritor. Con todo, la asunción de que no intervienen "personajes" en el ensayo puede ser descartada rápidamente si recordamos el Así habló Zaratustra de Nietzsche y el Ariel de Rodó, que tan bien conoció Díaz Rodríguez y cuyas estrategias dramáticas o pseudonarrativas reformuló en su colección ensayística Camino de perfección. ${ }^{3}$ Ahora bien, la única diferencia entre narrativa y ensayo que esto nos deja es la última: enunciación ficticia en una y enunciación real, "comunicativa" en otra.

Críticos recientes han tratado de distinguir novela y ensayo precisamente partiendo de semejante oposición o de una variante: "El sujeto de la escritura en la narrativa es siempre un narrador ... El sujeto de la escritura en el ensayo es siempre un autor" (Giordano 208). Lo cierto es que Picón-Febres, el lector de Díaz Rodríguez, no pareció tomarla en cuenta o simplemente no pudo percibirla en un texto como Ídolos rotos. Curiosamente, no es el único caso de un miembro del público que haya confundido personajes o narradores diazrodriguianos con el hombre que los produjo. ${ }^{4}$ Queda preguntarnos, entonces, qué impide que la recepción sea compatible con el sistema de ideas que ha originado a la obra. ¿Dónde comienza el malentendido?

Para responder a esta pregunta me parece oportuno analizar la segunda novela de Díaz Rodríguez, Sangre Patricia (1902), tan exitosa en sus días como Ídolos rotos y tan susceptible como ésta de ser leída "doctrinariamente".

${ }^{3}$ Sobre estas relaciones intertextuales, véase Miguel Gomes, Poéticas del ensayo venezolano del siglo XX. Tesis de doctorado (Stony Brook: State University of New York, 1993).

${ }^{3}$ Hecho que denuncia con sutileza Pedro-Emilio Coll (Paz Castillo 1:92). 
Antes de toda constatación, echemos un vistazo al plot. En un viaje por mar, de Caracas a París, muere súbitamente Belén Montenegro; su urna es arrojada al Atlántico. Tulio Arcos, que se ha casado con ella por poder, se entera de la noticia cuando la nave llega. Ocampo, joven médico positivista, decide cuidar de su camarada y hacer que olvide el incidente: sol, amistades, un viaje a Niza. El tratamiento falla y la única alternativa es un regreso a Venezuela, a la acción de la que el paciente, hacía mucho, se había apartado. Estalla una revuelta en el país lejano y el momento se hace propicio. Parte Tulio, pero la obsesión por Belén, por su fantasma acuático, ha ido creciendo y ya lo posee. El desenlace es un suicidio. Tulio, cuya voz interior le gritaba que "no podía quedarse viendo correr la vida, como se queda viendo pasar el agua del torrente un soñador o un idiota" (Narrativa 168), se deja caer al mar, perece sumergido, incapaz de ponerse a la altura de sus antepasados aristócratas, luchadores y legisladores, héroes del idealismo y del arielismo en su sentido más exacto ... Téngase en cuenta que su matrimonio ha sido celebrado "a través del océano, con un simple poder, a la manera yanqui, tal un feo negocio triste" (183) y no puede ser tildado sino de acto de calibanismo. El océano, con su "reserva de ideal", sus sirenas, sus diosas, sus misterios, devorará a Tulio en un simbólico cobro de cuentas por su apocamiento terrestre, utilitario. El error fundamental del último miembro de los Arcos ha sido no saber incorporar aquel torrente de agua a su interior, manteniéndose al margen, en la contemplación del idiota. Lo que pudo ser "espacio feliz", como diría Gaston Bachelard, se vuelve espacio fatal y vengativo: su salvación acaba con él.

La anterior no es una síntesis arbitraria. Detengámonos en Alejandro Martí, venezolano radicado en París, una de las amistades de Ocampo y Tulio, y podremos darnos cuenta de que, como músico, como síntesis del artista, ayuda a descifrar esta madeja de sucesos. Su lucha contra el mercantilismo, su huida de Nueva York - la "capital del cheque", como la llamó Darío- su actitud religiosa, su ingenuidad concuerdan con todos los imperativos que caracterizan el modernismo según el ya recordado libro diazrodriguiano Camino de perfección (especialmente, la pieza titulada "Paréntesis modernista, o ligero ensayo sobre el modernismo"). ¿Qué se dice de "Martí" - apellido tremendamente significativo entonces?: "Blanda luz mística bañó su fe y su arte, y la unión del arte con la fe completó la unión, ya realizada en él, del arte con la vida" (200). La comunión no presente en Tulio está aquí. Notemos la manera como se describe: es una experiencia que "baña", un bautismo. Ocampo, contradictor de Martí en cada tertulia, por otra parte, es un hombre a ras de tierra, apegado al sólido suelo incluso por impertinencia onomástica del narrador. ${ }^{5}$ El principio que Martí encarna queda manifiesto en un pasaje memorable del capítulo VII en que ofrece un concierto (211-12). Entre el asombrado público se encuentra Tulio Arcos, desde luego, que oye como una "nota" musical da forma a una "gota de agua" que hará surgir una "lluvia", un "río", "ondas", y así sucesivamente. La paronomasia nota-gota ha sido explotada brillantemente y establece una analogía entre la más abstracta de las artes y las figuraciones ondulatorias típicas de la imaginería modernista, ${ }^{6}$ que según palabras de Camino de

\footnotetext{
${ }^{5}$ Aún no se ha hecho un estudio detallado de la función de los nombres propios en la obra de Díaz Rodríguez, aunque, como se verá, podría ser muy fructífero.

${ }^{6}$ Recuérdese que el patrono mitológico y filosófico del movimiento es definido por Rodó como "forma del mar, numen del mar" en las primeras líneas de Motivos de Proteo (1909).
} 
perfección se oponía a la idea de "la línea recta", propia de académicos incapaces de apreciar gradaciones, sinestesias, "hibridez" y "lo relativo de las cosas" (13). La imposibilidad de Tulio de asimilar el mundo martiano - y de metamorfosearse él mismo en ser marino- explica su muerte por inmersión.

Lo que nos interesa, sin embargo, es apreciar cómo la dilución del protagonista se convierte en una dilución genérica del texto: la de las formas siempre definidas y "rectas" combatidas por el modernismo. En este sentido, la novela de Díaz Rodríguez pertenece al linaje no escaso en Hispanoamérica de lo que se ha denominado, no felizmente, "relato ensayístico", es decir, una narración donde el dominio del discurso mimético se debilita por la presencia desmesurada de un discurso reflexivo o conceptual (véase Leenhardt y Giordano 205-13). ¿Cómo hace patente Sangre patricia esa duplicidad, esa "hibridez"?

Un repaso del primer capítulo no da pie para dudar de la "pureza" narrativa de lo que leemos: presentación de Belén, descripción de su belleza y su muerte. Llegados al segundo, la situación cambia sutilmente: con ocasión de hacer un recuento del pasado de Tulio, una serie de dicotomías expuestas con desenfado delata una trama ideológica, un texto con vida más o menos independiente de la narración, que resulta familiar para nosotros así como lo fue para el lector de la época: lo "patricio" se opone a lo "bárbaro" (172), igual que en el Ariel de Rodó, publicado dos años antes, Ariel se oponía a Calibán. No tardaremos en encontrar expresiones como "moral de esclavos" (177), que remiten a un sistema filosófico archiconocido entonces - Nietzsche, presente explícitamente en otros textos de Díaz Rodríguez, como ya he señalado- y sentencias como "soñó hallarse en Florencia y despertó en Cartago" (178), que calcan el enfrentamiento París-Nueva York que hizo las delicias del Darío ensayista de Los raros. ¿Resultado de todo esto? Dentro de la novela empieza a entablarse un diálogo entre la representación del universo y su intelección. No es de extrañar que un lector acostumbrado a otros modernistas se dispusiera a enfrentarse a las páginas anteriores y las siguientes con actitudes similares a las requeridas por textos argumentativos, atribuyendo dichos novelescos al ser humano que los plasmó, hecho que ocurrió con Ídolos rotos.

Prosigamos con la lectura de los capítulos III, IV y V: el relato se desenvuelve desembarazado de todo "obstáculo". Sin embargo, en el VI, nos concentraremos en la figura ejemplar, ya descrita aquí, de Martí, con una curiosa conversación sobre España y la hispanidad de América que será retomada extensamente por Díaz Rodríguez en Camino de perfección y en otros ensayos como "Sangre de Hispania fecunda", de Sermones líricos. Estas catálisis suspenden largamente las acciones y recuerdan retóricamente la manera de analizar conceptos propia del "diálogo", género protoensayístico de antiguos y renacentistas. En el capítulo VII, el hibridismo es imposible de disimular: Martí y Ocampo discuten acerca de lo sobrenatural ("Ariel", digamos) y lo psicofísico ("Calibán"); según se afirma, ya nadie cree en sátiros y ninfas; hay una pérdida de idealismo, de ensoñación ... ¿Qué sucederá con las sirenas?

... si de la vida pasamos al arte, ¿podrá negarse en éste la existencia y el predominio de lo sobrenatural? ¿Acaso no es sobrenatural eso que los filósofos y críticos de hoy han dado en llamar lo Inconsciente? Algo sobrenatural preside a todo feliz alumbramiento artístico ... (210). 
La complementaridad con respecto a los ensayos de Díaz Rodríguez es notoria y no podríamos decir lo contrario, pues el discurso mimético se infiltra con menos intensidad en sus textos predominantemente argumentativos. Es cierto que el sujeto de la narrativa, la subjetividad presente en la expresión, es siempre un "narrador"; ha de admitirse, pese a ello, que en Sangre patricia el narrador y ciertos personajes se parecen ideológicamente casi tanto al autor de carne y hueso como la voz que encontraremos en Camino de perfección y otras obras de meditación previas y posteriores: eso justifica que tanto la narrativa como el ensayo diazrodriguianos hayan podido ser recibidos por igual como escritura adoctrinadora y comunicativa. Desarraigo de Tulio Arcos, desarraigo de Alberto Soria, desarraigo de Díaz Rodríguez: leída la novela como una especie de ensayo dramatizado o fabulado, era fácil que se intuyeran proyecciones autobiográficas y que se diera el salto (el escritor es el hablante) permisible en el ensayo y no en la novela. Curiosamente, en contra del modelo genérico personal que el autor presentaba a Picón-Febres, el pantextualismo de la época había orientado los gustos y las percepciones del público al extremo de que éste leyó libros más modernistas de lo que su propio progenitor concebía —engendros proteicos, formas engañosas, duales. La confusión se reforzaba si pensamos que "regionalistas" como Picón-Febres añadieron a los victoriosos esquemas del modernismo códigos supervivientes de una literatura transitiva, en la que las producciones literarias debían predicar.

¿Cómo comparar este fenómeno con otros contiguos, reconocibles en el mundonovismo posmodernista? En una novela modelo como Canaima (1935), hallaremos personajes que ejercen la función de "ensayista" y que podrían identificarse ideológicamente con el mismísimo Rómulo Gallegos, lo que ha sucedido una y otra vez entre múltiples comentaristas y seguidores políticos del "novelista". Echemos un vistazo a algunas cavilaciones de Manuel Ladera en el texto:

Tupuquén llaman a una hierba brava, más eficaz que el hacha y que el fuego para acabar con el monte tupido, pues donde ella se mete ya no crece otra cosa. Por aquí reinaba a sus anchas ... Otro tupuquén reina también por estas tierras: las llamadas riquezas del Yuruari, el purguo y el oro que quitan los brazos a la agricultura. Los brazos y el capital, que ya tampoco quiere invertirse en ella. Al purguo y al oro los llaman la bendición de esta tierra, pero yo creo que son la maldición. Despueblan los campos y no civilizan la selva ... (26).

La manida confrontación civilización-barbarie, tan explícita como en Sarmiento, perdura aquí, así como el pensamiento político que ya el autor se proponía llevar a la práctica - recordemos que al año siguiente de publicada la novela llega a ser Ministro de Instrucción Pública. Una revisión no muy detallista de ensayos galleguianos aparecidos ya en El Cojo Ilustrado descubriría un pensamiento y un discurso "laderista" desarrollados por el escritor desde muy temprano, antes, incluso, del personaje y de la ficción. La identificación parcial Ladera-Gallegos resulta así justificable fenomenológicamente.

¿Qué semejanzas y diferencias hay entre los procedimientos de Díaz Rodríguez y los de Gallegos? Son evidentes los parecidos técnicos: hemos hablado del personaje-ensayista y de los diálogos que se transforman, por su falta de espontaneidad, en verdaderos debates filosóficos. Las diferencias, en cambio, son más significativas. La plasmación imaginaria 
de un universo referencial es asumida en Sangre patricia de manera introvertida y en Canaima extrovertida. Existe en Ladera un énfasis comunicativo que apunta a una sociedad, a un país, a unas reformas específicas de ambos. El referente de Martí es eso llamado "arte", y la literatura, Sangre patricia misma, es una de sus manifestaciones, como el lector puede intuir. El modernismo se vale de un metalenguaje para afianzar la extraña disolución de la vida en el arte y viceversa, analogía suya de las más queridas. En esa línea de una poética transgresora debemos leer sus abusos de reflexión a lo largo de la situación narrativa. Las categorías puras, absolutas, pues, han de darse por eliminadas y la mejor manera de hacer efectivo este propósito es por medio de un "género" relativo, maleable y, por consiguiente, imposible de sujetar a cánones estrictos. ¿Ensayo? ¿Novela? Aunque la modalidad expresiva característica de uno de los dos tipos predomine, la respuesta más exacta sería "escritura". Una escritura omnipresente para la cual las formas tradicionales son un punto de partida, más bien un accidente y no una restricción. La novela de Gallegos, por el contrario, coincide con el ensayo no por una predilección pantextual. El imperativo transitivo exigía que ambos tipos se aproximaran, convertidos en dos métodos didácticos distintos, pero afines. Después de todo, según el Gallegos ensayista, el intelectual debía ser "educador o conductor de pueblos" (Rodríguez Ortiz 1989, 1:42).

\section{III}

Hemos analizado las condiciones en las que se rozan novela y ensayo en dos importantes autores de la primera mitad del siglo XX. Veamos ahora cómo resurge el diálogo intergenérico en otro par de escritores que han hecho aportaciones notables en ambos tipos literarios durante la segunda mitad del siglo.

El primero de ellos, Francisco Rivera, ha definido el ensayo como cuestión de "pensar, narrar y, mientras se narra, hacer poesía, Dichtung" ("Kenneth White y la posmodernidad", véase 1993). Lo que une su novela Voces al atardecer (1990), con sus abundantes piezas ensayísticas, sin embargo, no es la convivencia programática en un texto de formas expresivas asociadas por nuestra época con géneros diversos, sino algo situable simultáneamente "dentro" y "fuera" de la escritura. Una "ética" no puede adjudicarse a solas al ensayista o al novelista; cuando la mencionamos, de un modo u otro, involucramos al escritor, prescindiendo de los canales por los que haya preferido manifestarse.

Al descubrir en una novela la capacidad de juzgar moralmente es evidente que recurrimos al lenguaje figurado para sustituir nuestra capacidad como lectores por una palabra otra; proyectamos nuestra facultad sobre un objeto, el texto, y lo humanizamos. De hecho, en toda narración los hablantes imaginarios pronuncian oraciones imaginarias. Sus juicios, y no sólo su expresión, son emitidos en situaciones vitalmente hipotéticas. La ética que se desprenda de ellos, por fuerza, será imaginaria también, será literatura. El único vínculo posible entre las creencias del autor y su relato habrá de ser la consustanciación de este último con una parte específica del espectro referencial infinito del universo en el que el hombre haya vivido. Toda conexión ética que se haga entre una novela y un ensayo tiene que entenderse, entonces, como paraliteraria. Quien escribe un relato escoge un conjunto de problemas o es escogido por ellos. A partir del momento en que aparezca la escritura, la palabra novelesca creará al sujeto que se referirá a dichos problemas. Precioso 
en este sentido es lo que nos explica uno de los ensayos de Rivera, que trata de $L a$ consagración de la primavera, narración, según se nos dice, fallida y "aburrida":

Hay novelas que se apoderan del lector porque lo hacen entrever, a través de una cuidadosamente fabricada red de símbolos y figuras, las obsesiones y los mitos personales e impersonales que nutren la producción textual de un autor determinado. Hay otras, por el contrario, que desgraciadamente aburren al lector al darle la clara impresión de ser "novelizaciones" más o menos bien intencionadas de un material que debería recibir otro tipo de tratamiento: periodismo, memorias o ensayo. Esto no quiere decir que los ensayos de un Montaigne o un Huxley me parezcan menos dignos de consideración que las novelas de un Balzac o de un Beckett. Lo que quiere decir ... es que tiene que haber, y hasta ahora siempre ha habido, una diferencia ... entre la exposición de una teoría o la explicación de una vida real y la elaboración de un texto imaginativo ... $(1981,145)$.

¿Qué "defectos" en el caso de La consagración producen "aburrimiento"? "Excesiva discursividad ensayística", "incapacidad para escribir diálogos", "despliegue no estructural de referencias eruditas y pseudoeruditas" y "moralismo". Curiosamente, tal moralismo no depende de las ideas o preferencias políticas reales de Carpentier, sino de la dependencia psicolingüística inverosímil de sus seres de ficción con respecto a él. Esto se ve patente "en los supuestos monólogos de Vera y Enrique, los cuales se apartan de todo realismo por dos razones: primero, porque ambos personajes narradores se expresan exactamente igual (es decir, 'hablan' como el autor), y segundo, porque ni ellos, ni el narrador omnisciente que se esconde detrás han comprendido ... que existe una enorme diferencia estilística entre 'lo hablado' y 'lo escrito"' (149).

En efecto, si algo aleja Voces al atardecer de la escritura ensayística de Rivera es la puesta en práctica de los criterios con que Carpentier ha sido medido en el texto citado. Aunque los problemas en que se ven inmersos sus personajes no dejan de ser familares a los lectores de los ensayos que Rivera recoge en Entre el silencio y la palabra (1986) o La muerte de los dioses (1990), no será el novelista quien ahora "proponga" y "analice". Estamos ante seres de ficción que, simplemente, actúan desde sus circunstancias: reaccionan de modos diversos pero, sobre todo, lo hacen fieles a sus propias perspectivas. Si en los libros ensayísticos mencionados domina generalmente un punto de vista, el del hablante cogitativo, en Voces la pluralidad llega a ser un oxímoron: centro disperso. Éste se dará a conocer a través de locutores múltiples que se encuentran o surgen unos de otros y tienen, cada uno, autonomía de entendimiento y expresión. Los personajes y locutores pueden comportarse de una manera distinta al autor, hablan de manera diferente y esta verbalidad diferenciadora los identifica. Los puntos de vista del doctor Mauricio Finkelstain y sus amigos y pacientes Mariana y Pedro Salazar, de hecho, resultan distinguibles entre sí, no menos que sus idiolectos y los de los demás personajes inscritos en la memoria de estos tres subnarradores principales: los psiquiatras se expresan como psiquiatras; los escritores, como escritores; los pintores, como pintores: con deudas superficiales o profundas con sus conocimientos, intereses y jergas respectivas. Los nuevos ricos caraqueños de los años setenta y ochenta, asimismo, se debaten realistamente entre un español pomposo y la influencia mal asimilada del inglés atomizado de los mass media. Junto a estas variedades de la lengua verificamos muchas otras esperables en la Caracas de la segunda mitad del 
siglo XX. El estilo indirecto imbrica unas formas y otras de habla, siempre en tensión (37). Los personajes, incluso, perciben las particularidades lingüísticas de los otros y en más de una ocasión las problematizan, las convierten en parte primordial de sus relaciones $(57,112,170$ y passim $)$. Conciencia del lenguaje ajeno que es, a su vez, conciencia de la enunciación, de cómo la subjetividad se configura en las palabras y las sitúa en seres autónomos - tal es el arte del autor de Voces al atardecer, y nótese que ya el título apunta en esa dirección. Aunque los personajes - como en Sangre patricia-diserten una vez que otra sobre música, pintura o literatura, la novela de Rivera se aparta de la "discursividad ensayística" que hacía ver el ensayo sobre La consagración: discursividad ha de entenderse, entonces, como comunidad de ideas y voz de autor y hablante, reunidos promiscuamente.

Si comparamos la práctica novelística de Rivera con la teoría que él mismo expone en su papel de ensayista, llegaremos a la conclusión de que el modelo genérico que maneja es mimético en un sentido inusitado: un tipo literario puede distinguirse por su capacidad de reproducir más o menos fielmente un elemento del universo que le será negado a otro tipo. La novela "refleja", precisamente, la índole heteroglósica de la comunicación humana, a tal punto que ésta logra inclusive tematizarse en la trama: el lenguaje contradictorio de individuos en conflicto está presente en la médula de Voces al atardecer. Los ensayos de Rivera, como los de Montaigne o Huxley según su sugerencia, en cambio, son discursos que si bien ponen a dialogar ideas encontradas persiguen una síntesis: el empleo del singular en un título que se impone como summa, La búsqueda sin fin (1993) - la colección ensayística más reciente del autor- podría revelar la dirección única anhelada, en contraste con el título novelesco, que delata la importancia de lo plural.

El otro narrador y ensayista contemporáneo al que hacíamos referencia anteriormente es Oscar Rodríguez Ortiz. Como en el caso de Rivera, dos de sus mejores libros aparecieron el mismo año, 1990, y, aunque pertenecientes a géneros distintos, evidencian conexiones inomitibles en un estudio genológico intertextual como el que intentan abordar estas páginas. Sospecho que una de las claves comunes de Placebo y Horno Sapiens consiste en una estrategia formal transgenérica: la despersonalización. Sólo que puesta en un contexto ensayístico y en uno narrativo adquiere funciones incluso opuestas. En el ensayo, tipo literario asociado una y otra vez a la subjetividad casi autobiográfica, "doméstica", cuyo paradigma a lo largo de siglos ha sido Montaigne, una enunciación despersonalizada puede tener dos resultados: o el acercamiento del género a la objetividad científica $y$, por lo tanto, su disolución en discursos no tenidos por "literarios", o el surgimiento de un "antiensayo", que trata de contradecir un rasgo vinculado a las definiciones tipológicas tradicionales. El caso de Placebo, creo, es el segundo.

El hablante de esta colección de textos acerca del "imaginario de la contemporaneidad" no deja huellas lingüísticas o acotaciones que sirvan para hacer de él un personaje o semipersonaje, como sucede con muchísimos ensayistas. De Díaz Rodríguez sabemos, por sus escritos de meditación, que fue un viajero inveterado, un modernista confeso y que cultivó ciertas amistades con nombre y apellido; mediante sus artículos, Gallegos nos pone al tanto de cómo compilaba materiales para sus novelas, cómo se definía oblicuamente como educador del pueblo o qué pensaba de sus amigos juveniles de La Alborada; del Rivera ensayista se entresacan facetas biografizables como la del profesor de literatura, el lingüista o el hombre familiarizado con el mundo norteamericano ... Placebo, no obstante, 
poco o nada revela del individuo que echa a andar la maquinaria verbal ensayística. Las oraciones más características del libro son impersonales ${ }^{7}$ hasta en sus variantes más sofisticadas, en las que la ausencia de persona no es gramatical, sino conceptual: las cosas pasan a sustituir a los seres humanos. El hablante no "cree" ni "opina que", sino que "las Apostillas a 'El nombre de la rosa' permiten la libre interpretación" (52); "el estereotipo dice que en este momento resulta necesario invocar una palabra mediadora" (60); o "el hecho no proclama la verdad de san MacLuhan, verifica sólo el tormento contemporáneo" (70): los libros, las abstracciones y lo inanimado en general adquieren propiedades humanas, especialmente ideológicas y verbales, compensando el vacío de sujeto aparente en esta prosa.

La despersonalización en Horno Sapiens difiere de la de Placebo desde una perspectiva enunciativa: no hay oraciones impersonales o abstracciones personificadas sencillamente porque la narrativa implica una anulación del hombre que escribe, ya sustituido desde el principio por una voz textual de independencia prácticamente absoluta. A tal extremo llega esta autonomía que Rodríguez Ortiz opta por el uso de un pseudónimo: así, a la distancia con respecto al autor que supone la narración en primera persona de un joven huérfano, se agrega la presencia de un tal "Maurice Lambert" que, según la contracubierta, fue un "autor francés nacido en la primera década del siglo". El anonimato pseudonímico no tiene en este caso como objetivo el ocultamiento total de la existencia del escritor real, pues todo en el nombre ficticio escogido desprende un tufillo sospechoso de artificio Blanchot y un personaje de Balzac saltan a la vista del lector prevenido, así como el nombre del traductor "José María Valleverde" resulta una variación humorística obvia de José María Valverde. El broche de oro lo pone la contracubierta, que nos recuerda que Horno Sapiens fue publicado por Lambert "dentro del furor y la polémica provocados por un conjunto de obras de corte erótico generalmente suscritas con seudónimos" ...

El nombre falso, creo, es el único procedimiento posible de una estética como la que también produjo Placebo - pero se trata de un modus operandi que reconoce una diferencia entre narrativa y ensayo: usar un pseudónimo es reforzar la naturaleza ficticia del texto lingüístico, cuya capacidad comunicativa, más que nunca, se hace "pseudo", es decir, fingida, literaria. Nada de esto aparece en Placebo, que tendrá un destino inverso: se literaturiza a través del lenguaje poético - la prosopopeya es, recordémoslo, una figura. El modelo genológico que desarrolla la escritura de Rodríguez Ortiz, en pocas palabras, es una curiosa variedad de nihilismo: si su novela es incluso tradicional en cuanto a afiliaciones (narrativa erótica por tema y por ciertas convenciones como la del nombre "secreto" del autor; fragmentarismo y collage de raíz vanguardista; novela de formación "inversa" o "perversa", ${ }^{8}$ etc.), su libro de ensayos es una negación asombrosa de patrones ensayísticos previos. En el conjunto de su obra, entonces, ocupa el lugar de un "antigénero".

\footnotetext{
7 "No es raro que el extraño y buscado bien de la dicha sea conseguido por los filósoficos ..." (26);

"Acaso hay alguna mayor desconfianza hacia el libro ..." (50); "Se sabe que las utopías renacentistas ..." (68), etc.

${ }^{8}$ Sobre el tema de la infancia y la literatura es sumamente valioso uno de los ensayos de Placebo, "Feliz edad, tiempo desdichado".
} 
¿Conclusiones? La convivencia de genologías como las de Rodríguez Ortiz y Rivera nos habla de un momento curioso en la literatura venezolana de fin de siglo, en la que el rupturismo vanguardista se produce simultáneo a preferencias estéticas milenarias como la mimesis. Si este original multifacetismo se compara con las tendencias contrastantes que suponen las respectivas teorías de los géneros de Díaz Rodríguez y Gallegos, tendremos un cuadro de extremada riqueza y ninguna monotonía: tanto el ensayo como la novela en Venezuela aspiran durante el siglo XX a ser universales en inclinaciones y fisonomía. Esto, al menos, en cuatro de sus cultores más memorables.

\section{BIBLIOGRAFÍA}

Díaz Rodríguez, Manuel. Camino de perfección (1910). Caracas-Madrid: Edime, 1968. Narrativa y ensayo. Orlando Araujo, editor. Caracas: Biblioteca Ayacucho, 1982. Sermones líricos (1918). Caracas-Barcelona: Ediciones Nueva Cádiz, 1955.

Giordano, Jaime. "Sobre novela y ensayo en Hispanoamérica". La edad de la náusea. Santiago de Chile: Monografías del Maitén, 1985.

Guillén, Claudio. Entre lo uno y lo diverso. Introducción a la literatura comparada. Barcelona: Editorial Crítica, 1985.

Jolles, André. Formas simples. Traducción Rosemary Kempf Titze. Santiago de Chile: Editorial Universitaria, 1972.

Leenhardt, Jacques. "Función de la estructura ensayística en la novela hispanoamericana". Revista de estudios hispánicos 7 (1980), 9-17.

Lévy, Isaac Jack y Juan Loveluck, editores. El ensayo hispánico. Hispanic Studies 3. Columbia: University of South Carolina, 1984.

Martínez-Bonati, Félix. Fictive Discourse and the Structures of Literature. A Phenomenological Approach. Traducción Philip W. Silver. (Versión muy aumentada de La estructura de la obra literaria 1960.) Ithaca-Londres: Cornell University Press, 1981.

Paz Castillo, Fernando, editor. Manuel Díaz Rodríguez entre contemporáneos (2 volúmenes). Caracas: Monte Avila Editores, 1973.

Rivera, Francisco. Inscripciones. Caracas: Fundarte, 1981. La bủsqueda sin fin. Caracas: Monte Ávila Editores, 1993. Voces al atardecer. Caracas: Planeta, 1990.

Rodríguez Ortiz, Oscar, editor. Ensayistas venezolanos del siglo XX: una antología (2 volúmenes). Caracas: Contraloría General de la República, 1989. [Maurice Lambert, pseudónimo]. Horno Sapiens. Caracas: Alfadil, 1990. Placebo. Caracas: Fundarte, 1990.

Yurkievich, Saúl. Celebración del modernismo. Barcelona: Tusquets, 1976. 